\title{
A PRÁXIS MÉDICA NO PRONTO ATENDIMENTO DIANTE DO PACIENTE COM SEQUELAS CRÔNICAS: CULPA, TEMOR E COMPAIXÃO
}

\author{
THE MEDICAL PRAXIS IN THE EMERGENCY CARE IN THE PRESENCE OF THE \\ PATIENT WITH CHRONIC SEQUELAE: GUILT, FEAR AND COMPASSION
}

LA PRAXIS MÉDICA EN SALAS DE URGENCIA FRENTE AL PACIENTE CON

SECUELAS CRÓNICAS: CULPA, TEMORY COMPASIÓN

\author{
Janaína de Souza Aredes ${ }^{1}$ \\ Karla Cristina Giacomin ${ }^{2}$ \\ Josélia Oliveira Araújo Firmo ${ }^{3}$
}

Resumo Qual é a relação entre as urgências e o cuidado crônico? Esta questão, aparentemente paradoxal, foi abordada em uma etnografia realizada no maior hospital de pronto socorro de uma metrópole brasileira, a qual investigou o cuidado médico desde a admissão até a ratificação da condição clínico-funcional do paciente sequelado grave. Entre dezembro de 2012 e agosto de 2013 foram realizadas observação participante e entrevistas com 43 médicos: 25 homens e 18 mulheres, de 28 a 69 anos. A análise, guiada pelo modelo dos signos, significados e ações, levou à constatação de que o cuidado varia segundo o contexto: na 'porta de entrada' e no 'centro de terapia intensiva' luta-se intensamente pela manutenção da vida; no setor 'crônicos', cuida-se de pessoas que sobrevivem, mas com alto grau de dependência. Para o médico, 'vida' significa a recuperação da funcionalidade prévia, enquanto a sobrevida com dependência seria uma 'morte em vida'. O médico se esquiva de lidar com um ser humano altamente limitado, pois sente-se de algum modo culpado pelo quadro, embora se compadeça diante do paciente que demanda cuidados crônicos. A insuficiência de uma rede de cuidados continuados e a falta de formação paliativista do médico geram sofrimentos a quem cuida e a quem é cuidado.

Palavras-chave cuidados de saúde; quadro crônico; incapacidade; pronto socorro.
Abstract What is the relationship between urgencies and chronic care? This question, which is apparently paradoxical, was approached in an ethnography conducted at the largest emergency care hospital of a Brazilian metropolis; the ethnography investigated medical care from admission to the confirmation of the clinical and functional condition of the patient with severe sequelae. Between December 2012 and August 2013, we conducted interviews and participant observation with 43 physicians: 25 men and 18 women, aged between 28 and 69 years. The analysis, which was guided by the signs, meanings and actions model, led to the realization that the care varies according to the context: at the 'gateway' and at the 'intensive therapy center', the struggle to maintain life is intense; at the "chronic patient" sector, care is provided to people who survive, but who have a high degree of dependence. For the physician, 'life' means regaining previous function, while survival with dependence would mean a 'living death.' The physician refrains from dealing with a highly-limited human being, for he/she feels somehow guilty of the clinical picture, even though he/she feels compassion towards the patient who requires chronic care. The insufficiency of a long-term care network and the lack of palliative training on the part of the physicians cause suffering in those who care and in those who are cared for.

Keywords health care; chronic clinical picture; disability; emergency care. 


\section{Introdução}

A medicina moderna luta para prolongar a vida do paciente e espera com o seu cuidado preservar-lhe a funcionalidade (Fontes e Martins, 2015), ou seja, as funções do corpo, as atividades e a participação social do indivíduo (Classificação Internacional de Funcionalidade, Incapacidade e Saúde, 2004). Contudo, a evolução biotecnológica e os cuidados pré, per e pós-hospitalares nas urgências têm assegurado a sobrevivência de pessoas, inclusive aquelas sem prognóstico de cura (Silva e Menezes, 2015) e com sequelas funcionais definitivas muito graves, em decorrência de doenças crônicas não transmissíveis (DCNT) e da violência - urbana, interpessoal, automobilística e motociclística (Diniz, Pinheiro e Proietti, 2015; Deslandes, 2002). Tal fato contradiz os preceitos biomédicos curativos e desafia a prática dos cuidados médicos.

Estudos sobre a temática da prática do cuidado exploram o contexto da terapia intensiva (Frazee et al., 2015), a obstinação terapêutica (Neville et al., 2015), a abordagem do paciente oncológico (Carrera e Olver, 2015), a atuação do profissional da enfermagem (Silva e Ramos, 2014; Nascimento et al., 2015) ou ainda o atendimento à pessoa idosa (Caldas et al., 2015). Porém, na literatura consultada, não foram encontradas pesquisas que abordassem, especificamente, a atuação médica em pacientes com adoecimentos de longa duração no contexto das urgências.

Assim, o estudo que deu origem a este artigo buscou compreender a percepção do profissional médico acerca do cuidado ao paciente grave atendido no pronto atendimento, desde a admissão até a alta ou o óbito, ou quando seja definitivamente ratificada uma sequela crônica que incorra na dependência definitiva de aparelhos e da ajuda humana.

\section{A práxis e o cuidado médico no contexto hospitalar: a luta pela vida contra a morte na sociedade ocidental}

A lógica funcional da sociedade ocidental enfatiza o progresso, a superprodução e o desenvolvimento. Nela, é função basilar dos hospitais prestar serviços cujos objetivos são: garantir a saúde, curar as doenças e evitar a morte (Menezes, 2004), favorecendo a vida produtiva dos indivíduos. Por isso, além de aliviar sofrimentos, os hospitais podem ser considerados como indicadores de desenvolvimento econômico de uma sociedade (Rodrigues, 2006).

Nessa organização médica e social (Menezes, 2004), o médico passou a ter o poder de decisão e intervenção apoiado e justificado pela instituição hospitalar (Foucault, 2003). O acelerado desenvolvimento científico da biotecnologia para prolongar a vida resultou no advento de espaços específicos de cuidado intensivo (Menezes, 2004) e, mais recentemente, na implantação do 
Serviço de Atendimento Móvel de Urgência (Samu), uma vez que foi possível interligar uma central telefônica de chamados de urgência, planejar a atuação no território e oferecer ambulâncias equipadas com recursos e insumos para atender pessoas com traumas simples e permitir até a ressuscitação cardiorrespiratória. Esse atendimento pré-hospitalar é considerado essencial para a sobrevivência de vítimas de acidente e violência, especialmente pela rapidez e precocidade do atendimento (Seminotti e Neves, 2014).

Ao mesmo tempo que o hospital se transforma em local de cuidados médicos, ele pretende se transfigurar em um espaço cuja função é eliminar a dor e a morte (Rodrigues, 2006). Contudo, a depender da gravidade das lesões, nem a agilidade e a eficiência do atendimento de emergência nem todo o aparato propedêutico e terapêutico hospitalar revelam-se suficientes para impedir a morte ou prevenir sequelas crônicas incapacitantes, desfechos que desafiam a práxis e o cuidado médico.

Entendem-se como práxis as práticas cujo sentido dirige-se ao estabelecimento de uma intencionalidade, solicita uma intervenção planejada e científica sobre o objeto, ensejando a transformação da realidade social (Franco, 2015). Apesar disso, Carr (1996, p. 101) pondera que, ainda que se planeje a intervenção, os resultados dessa atuação permanecem imprevisíveis, pois "nem a teoria, nem a prática tem anterioridade, cada uma modifica e revisa continuamente a outra".

Por cuidado médico compreende-se uma tentativa de reconstruir uma atenção integral à saúde dos indivíduos, com base nos problemas e tensões identificados, bem como de "recompor competências, relações e implicações ora fragmentadas, empobrecidas e desconexas" (Ayres, 2009, p. 18).

Ao se investigar a práxis (Franco, 2015; Carr, 1996) e a dinâmica do cuidado médico (Ayres, 2009), questões culturais permeiam a compreensão do processo saúde-enfermidade ou do tratamento entre profissionais e usuários. Nesse percurso, notam-se interações humanas que existem fora dos indivíduos e entre eles, e o que se revela é a vida cotidiana em ato (Kleinman, 1980).

No estudo que originou este artigo, assumiu-se o corpo, a vida e a morte como alguns desses fenômenos socioculturais que ultrapassam a dimensão biológica do homem e repercutem na práxis e no cuidado médico. Com significados diversos e polissêmicos, sempre associados a contextos, sujeitos e universos simbólicos próprios, esses fenômenos são consonantes ao conceito de fato social total proposto por Mauss (2011). Para este autor, o fato social total diz respeito à integração de diferentes esferas constitutivas da vida social, para que haja uma compreensão transversal. É válido destacar que essa totalidade em que os fenômenos sociais estão inseridos só pode ser apreendida na experiência vivida do indivíduo, na qual este irá construir suas percepções a respeito de determinado fenômeno da vida social (Mauss, 2011). Daí o interesse em se investigar como o profissional médico percebe o cuidado prodigado ao paciente grave atendido no pronto atendimento, que resulta em algum dano ou sequela definitiva ou mesmo no óbito do paciente. 


\section{Percurso metodológico}

O estudo aqui apresentado foi do tipo qualitativo ${ }^{4}$ e baseou-se nos pressupostos da antropologia médica hermenêutica (Geertz, 1989), que analisa as relações humanas segundo um processo de significação imbricado às perspectivas individual e coletiva (Corin, Uchôa e Bibeau, 1992).

Para Kleinman (1980), ao explorar o território que se deseja estudar deve-se ter como foco a doença-experiência, as relações médico-paciente e o processo de cura/cuidado. Analisa-se, então, como esses elementos afetam e como são influenciados no contexto em que estão inseridos.

\section{Área e população de estudo}

O território de investigação, situado no hipercentro da cidade de Belo Horizonte, é um dos maiores hospitais de pronto atendimento ao politrauma e a queimados da América Latina e referência para todo o estado de Minas Gerais. É certificado e credenciado pelos ministérios da Saúde e da Educação e habilitado como Centro de Referência em Alta Complexidade TraumatoOrtopédica, isto por se configurar como uma instituição de ensino, desenvolvimento de pesquisas e tecnologias em saúde, treinamento e formação de recursos humanos. Como já discorria Foucault sobre a instituição hospitalar: "não é somente um lugar de cura, mas também de registro, acúmulo e formação de saber" (Foucault, 2003, p. 110).

A instituição possui cerca de seiscentos médicos e cinquenta residentes. A população de estudo para a pesquisa aqui apresentada constituiu-se de 43 médicos plantonistas de diferentes especialidades - 25 homens e 18 mulheres, entre 28 e 69 anos - que atuam em setores específicos para pacientes graves com risco de morte e/ou de incapacidades definitivas.

\section{Coleta e análise dos dados}

Na etnografia (Geertz, 1989) que deu origem a este artigo, foi necessário portar indumentária própria do território de investigação, apropriar-se de um vocabulário novo e específico e participar de atividades típicas da rotina do serviço: empurrar macas, procurar funcionários, buscar instrumentais cirúrgicos e até discutir casos clínicos. Usar jaleco branco de manga comprida, calçado fechado e crachá de identificação funcionou como um dispositivo para entrar e circular no hospital (Aredes et al.,2017). A vestimenta, de modo especial, representava um símbolo potente de pertencimento ao grupo dos médicos, experiência similar à de Chazan (2005). 
Durante nove meses de investigação (dezembro de 2012 a agosto de 2013), foi realizada uma observação participante - em plantões noturnos e diurnos - direcionada, especialmente, ao acompanhamento do fluxo dos pacientes e da rotina do trabalho dos médicos. A relação foi mediada pela cumplicidade entre pesquisador e interlocutor, o que viabilizou, de modo eficaz, a realização do trabalho de campo (Aredes et al., 2017).

As entrevistas, com duração média de sessenta minutos, foram guiadas por roteiro semiestruturado, e os participantes foram selecionados segundo o método conhecido como 'bola de neve' (Patton, 2002). Determinou-se o número final de entrevistados pelo critério de saturação (Fontanella et al., 2011).

Todas as entrevistas foram gravadas e posteriormente transcritas de forma literal. A leitura exaustiva desses relatos e das anotações de campo permitiu a análise dos dados, orientada pelo modelo de 'signos, significados e ações' (Corin, Uchôa e Bibeau, 1992). Nele, analisam-se os comportamentos concretos dos indivíduos (profissionais médicos) a fim de identificar e compreender as lógicas conceituais agregadas a tais ações (o cuidado a pessoas com sequelas definitivas), bem como os distintos fatores que os influenciam. Essa abordagem viabiliza o acesso às lógicas conceituais intrínsecas a um grupo específico que as utiliza para compreender o processo saúde-doença-cuidado.

Para assegurar o anonimato dos entrevistados, os profissionais foram identificados, respectivamente, por ordem da entrevista, especialidade médica, sexo e idade. Todos eles leram e assinaram o termo de consentimento livre e esclarecido, e não houve recusa no recrutamento. Na percepção dos médicos, o cumprimento rigoroso dos procedimentos éticos favoreceu a atuação etnográfica e conferiu credibilidade ao trabalho. Para eles, o termo de consentimento dá uma segurança de que a pesquisa que será realizada na instituição constitui um trabalho sério e aplicável (Aredes et al., 2017).

O estudo aqui apresentado partiu de um projeto maior, aprovado pelos Comitês de Ética da Universidade Federal de Minas Gerais e da Fundação Hospitalar do Estado de Minas Gerais e está em conformidade com a resolução n. 466/2012 do Conselho Nacional de Saúde.

\section{Resultados e discussão}

Da análise etnográfica emergiram as categorias: “O percurso do cuidado médico ao paciente 'crônico-sequelado' em um pronto socorro: o médico diante dos limites da vida e da morte"; e "A urgência como um 'não lugar' para a cronicidade: os dilemas do 'Criador' diante da 'Criatura' na práxis médica". 


\section{O percurso do cuidado médico ao paciente 'crônico-sequelado' em um pronto socorro: o médico diante dos limites da vida e da morte}

Esta categoria apresenta a percepção do médico sobre o cuidado ao paciente 'crônico-sequelado' em três contextos identificados durante a etnografia: o pronto atendimento, aqui denominado 'porta de entrada'; o cuidado intensivo ('CTI'); e o setor 'crônicos', que se refere à Unidade de Cuidados Progressivos (UCP). Este último é dedicado a pacientes que paradoxalmente demandam cuidados intensivos e paliativos, pois não apresentam qualquer prognóstico de cura. Em cada cenário, a percepção do médico sobre o cuidado e sobre a sua atuação será apresentada nas suas características peculiares.

$\mathrm{Na}$ 'porta de entrada', a agilidade no atendimento é fundamental para o prognóstico, a recuperação e o restabelecimento imediato da vida (Giacomo, 2011). No diário de campo, estão registrados os signos 'desafio', 'adrenalina', 'tomada de decisão imediata', que expressam a escolha dos médicos em trabalhar nesse contexto. Todos os esforços técnicos e humanos do médico são canalizados para tomar decisões sob pressão e em tempo hábil (Deslandes, 2002), que definirão o prognóstico do paciente. O pensar e o agir dos profissionais referem-se ao cumprimento da expectativa atribuída ao seu papel de evitar a morte, como nestes dizeres: "não posso deixar o paciente morrer na minha frente sabendo que foi por algo que deixei de fazer, esse é o meu trabalho"; "fizemos um juramento pela vida dos pacientes" (diário de campo, de 2013). Este profissional explicou:

Ali no póli tem um paciente extremamente grave, está morrendo. (...) se a gente não fizer nada, ele vai morrer, mas se a gente optar por fazer alguma coisa, acho que ele vai morrer também na mesa cirúrgica. (...) Meu dever é tentar resolver o problema cirurgicamente, se o doente vai aguentar ou não aquela situação é outra coisa (E11, cirurgia geral, M, 39 anos).

De acordo com Deslandes (2002), por um lado o profissional vivencia um trabalho que é emocionante e recompensador; por outro, trata-se de um trabalho conflituoso, desgastante e estressante. A angústia do plantonista expressa o receio do não cumprimento da sua função, a qual respeita o modelo biomédico (Camargo, 2013) que orienta tratar a lesão biológica sem refletir sobre outras consequências, inclusive a impossibilidade de cura.

O segundo contexto ('CTI') inclui os setores de cuidado intensivo destinados a pacientes com instabilidade clínica e/ou hemodinâmica (Silva e Menezes, 2015), potencialmente recuperáveis e que demandam diferentes aparatos técnicos e humanos, como esclareceu este médico: 
Aqui [CTI] eu sinto que eu tenho um controle maior de tudo, na maioria das vezes eu sei o que vai acontecer nas horas seguintes com o paciente (...). Vários parâmetros estão monitorizados (...). Isso me dá mais segurança (E41, clínica médica, M, 38 anos).

$\mathrm{O}$ 'controle' das doenças é mediado por ações disciplinares que visam à cura, ao prolongamento e/ou à manutenção da vida (Silva e Menezes, 2015) e sustentam o poder da instituição hospitalar (Foucault, 2003). Contudo, o cuidado intensivo pode resultar em ainda maior fragmentação e objetivação do paciente (Silva e Menezes, 2015), além de contribuir para a sobrevivência de pessoas gravemente sequeladas. Quando isso ocorre, observa-se a resistência dos profissionais e residentes em lidar com esses pacientes, como neste relato:

Essa ojeriza que os residentes, as pessoas mais jovens, têm pelo andar ('crônicos') é porque você topa com uma fase... em que você fez tudo pela pessoa lá embaixo ('porta de entrada'), você fez tudo para salvar a vida ('CTI'), agora aqui no andar ('crônicos') você vai ver o resultado do que você fez lá embaixo. (...) Em muitas cirurgias não adiantou nada, e o que você vai ver é gente vegetando, e o estrago que isso traz para a sociedade, para as famílias. Isso é uma coisa que as pessoas não querem ver, chegar naquele lado deprimente (E32, clínica médica, F, 56 anos).

O setor 'crônicos' destina-se a pacientes sem prognóstico de cura. Os médicos denominam esses pacientes como 'crônico-sequelados', referindo-se a alguém que experimenta a dependência definitiva da ajuda humana e de aparelhos, o isolamento social e a falta de possibilidade de interação com o meio (Aredes e Modesto, 2016), os quais podem obstruir a participação plena e efetiva do sujeito na sociedade (Classificação Internacional de Funcionalidade, Incapacidade e Saúde, 2004).

Os pacientes cuidados neste setor refletem os resultados da cobrança imposta aos médicos no meio acadêmico e na sociedade de ter de evitar a morte a qualquer custo (Aredes e Modesto, 2016; Silva e Menezes, 2015; Kovács, 2014). Todavia, a visão de pessoas dependentes pode ser difícil de suportar, não tanto pelos custos sociais e financeiros que impõem, mas pelo significado apreendido por quem os assiste - na maioria das vezes, profissionais de saúde jovens e funcionalmente independentes (Giacomin e Firmo, 2015).

Conforme sumarizado no Quadro 1, em cada contexto de atuação a percepção do médico sobre quais seriam os mecanismos do cuidado aparece sempre balizada pelos conceitos êmicos de Vida e de Morte, como nos excertos a seguir:

Viver é: alimentar bem, não sentir dor, sentir bem-estar, socializar, fazer práticas físicas, sexo etc. A partir do momento que as pessoas perdem a capacidade de fazer isso, será que isso é uma boa qualidade de vida? (E27, clínica médica, M, 34 anos). 
O conceito clínico de morte é a parada de funcionamento do cérebro (...). Mas isso é muito questionável na prática da medicina, porque a gente (...) vê algumas coisas acontecendo no dia a dia que não tem explicação, a ciência não tem explicação (E28, terapia intensiva, F, 49 anos).

Eu também vejo a morte [biológica] como um alívio para o sofrimento, levando em consideração principalmente o local onde eu trabalho (unidade de crônicos) (E30, clínica médica, F, 44 anos).

Nota-se que as definições de Vida e Morte estão alicerçadas em perspectivas técnicas, sociais e morais (Silva e Menezes, 2015). Como 'fenômenos sociais totais' (Mauss, 2011), Vida e Morte são de difícil conceituação, pois extrapolam a dimensão biológica, envolvem dinâmicas socioculturais específicas e reverberam na experiência vivida do indivíduo. A mesma instituição hospitalar que visa manter a vida contribui para tornar a morte a tal ponto silenciada, regulada e rotinizada que culmina na sua banalização (Silva e Menezes, 2015; Kovács, 2014).

\begin{tabular}{|c|c|c|c|}
\hline \multicolumn{4}{|c|}{ Evolução do cuidado ao paciente atendido no Pronto Atendimento, Belo Horizonte, 2013} \\
\hline Critério/Contexto & Porta de Entrada & CTI & Crônicos (UCP)* \\
\hline Atuação do médico & $\begin{array}{l}\text { Tomada rápida } \\
\text { de decisão }\end{array}$ & $\begin{array}{l}\text { Propedêutica } \\
\text { e controle }\end{array}$ & Terapia intensiva crônica \\
\hline Foco do cuidado & $\begin{array}{l}\text { Restabelecimento } \\
\text { vital imediato }\end{array}$ & $\begin{array}{l}\text { Restabelecimento } \\
\text { vital progressivo }\end{array}$ & $\begin{array}{l}\text { Sobrevida com ajuda } \\
\text { de recursos técnicos } \\
\text { e humanos }\end{array}$ \\
\hline Mecanismo de cuidado & $\begin{array}{l}\text { Aplicação irrefletida do } \\
\text { modelo biomédico }\end{array}$ & $\begin{array}{l}\text { Utilização de todos os } \\
\text { recursos biotecnológicos }\end{array}$ & $\begin{array}{l}\text { Dúvida/Gestão de } \\
\text { complicações/Conforto } \\
\text { e Paliação }\end{array}$ \\
\hline $\begin{array}{l}\text { Determinante do } \\
\text { êxito ou do fracasso } \\
\text { do cuidado }\end{array}$ & $\begin{array}{l}\text { Tempo decorrido } \\
\text { entre o trauma/lesão } \\
\text { e o atendimento }\end{array}$ & $\begin{array}{l}\text { Evolução da condição } \\
\text { que gerou a internação }\end{array}$ & $\begin{array}{l}\text { Falta de evolução na } \\
\text { recuperação funcional }\end{array}$ \\
\hline $\begin{array}{l}\text { Entendimento sobre } \\
\text { a Vida do paciente } \\
\text { na urgência }\end{array}$ & $\begin{array}{l}\text { Recuperável: } \\
\text { luta pela vida }\end{array}$ & $\begin{array}{l}\text { Potencialmente } \\
\text { recuperável: } \\
\text { luta pela vida }\end{array}$ & $\begin{array}{l}\text { Sem prognóstico de } \\
\text { recuperação funcional: } \\
\text { conflitos diante da } \\
\text { limitação de cuidados }\end{array}$ \\
\hline $\begin{array}{l}\text { Entendimento sobre } \\
\text { a Morte do paciente } \\
\text { na urgência }\end{array}$ & Fracasso & Fracasso & Fracasso/Alívio \\
\hline
\end{tabular}

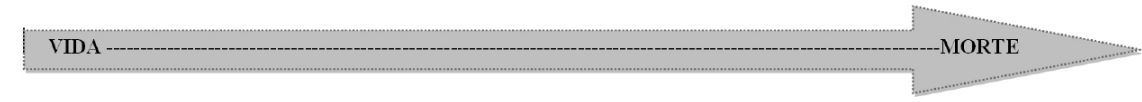

*UCP: unidade de tratamento intensivo destinada ao cuidado de pacientes sem possibilidades de cura.

Fonte: As autoras.

Nota: UCP - unidade de tratamento intensivo destinada ao cuidado de

pacientes sem possibilidades de cura; CTI - cuidado intensivo. 
Ainda nessa direção, o cuidado médico fundamenta-se no conceito biomédico da incapacidade funcional (Classificação Internacional de Funcionalidade, Incapacidade e Saúde, 2004) e se associa a perspectivas culturais, políticas e socioeconômicas, como a assistência à saúde e a medicalização da vida (Gurgel, 2007). Tal panorama também repercute na instituição, pois pacientes que demandam cuidados crônicos não encontram lugar em um contexto de urgência e expõem o médico a dilemas, como apresentado na próxima categoria analítica.

\section{A urgência como um ‘não lugar' para a cronicidade: os dilemas do 'Criador’ diante da 'Criatura' na práxis médica}

Esta categoria apresenta a que os médicos atribuem a etnoetiologia - compreendida como origem ou causa (Calvasina et al., 2007) - do paciente 'crônico-sequelado', bem como os signos e significados que o caracterizam. O pronto atendimento constitui-se como um 'não lugar' (Augé, 1994) para a cronicidade (Canesqui, 2013), e por essa circunstância emergem dilemas no cuidado médico.

Perguntados sobre como percebem a gênese de um paciente 'crônicosequelado', médicos de diferentes especialidades e setores explicaram:

Antigamente o povo dava tiro na cabeça para matar em ajuste de contas, hoje eles dão tiro na coluna para o cara ficar paraplégico, tetraplégico. (...) Para o crime organizado não interessa que o paciente morra, interessa que ele fique sequelado, que ele sofra (...). O paciente está consciente, mas não mexe, não faz nada, sofrimento e dependência muito grande. Para algumas pessoas, hoje a morte é vista como punição, mas não 'a morte' em si, mas o morrer (E33, terapia intensiva, F, 34 anos).

O paciente antigamente morria na cena [do trauma], ele chegava ao hospital todo arrebentado (...). E à medida que foram surgindo essas técnicas (atendimento préhospitalar), que realmente são úteis porque salvam vidas, mas ao mesmo tempo surgiu uma legião de sequelados. Então o terceiro andar [unidade de crônicos] surgiu da necessidade [de cuidados prolongados]. A medicina criou um novo tipo de paciente: o altamente sequelado. Esse paciente antes morria, alguns tinham a sorte de não morrer, ou azar, porque fica aqui sofrendo e depois de um tempo morre. E os meios legais e tudo, a gente não tem uma base científica: "ah, esse pode morrer, aquele não pode" (E29, cardiologia, M, 63 anos).

Eu acho que tem casos que realmente a gente não gosta de perder. Não que eu encare a morte como um jogo, uma queda de braço, (...) mas eu também não tenho sangue de barata para chegar e falar: "o paciente tá parando o tempo todo, então é melhor você perder" (E22, clínica médica, M, 33 anos). 
Assim, quanto à etnoetiologia (Calvasina et al., 2007) desse paciente, os médicos enfatizaram:

- fatores relacionados à morbimortalidade por causas externas, especialmente aquela proveniente da violência, uma constante nos serviços de saúde pública do Brasil (Murray, Cerqueira e Kahn, 2013);

- a evolução da medicina: o médico se sente corresponsável pela criação de um ser humano incapacitado e socialmente improdutivo; afinal, o progresso biotecnológico oferece maiores chances de sobrevida aos pacientes críticos (Diniz, Pinheiro e Proietti, 2015; Kovács, 2014), e o Serviço Móvel de Urgência (Samu) viabiliza o atendimento pré-hospitalar rápido e precoce - condição essencial para a sobrevivência de vítimas de acidente e violência (Seminotti e Neves, 2014; Baruzzi e Ikeoka, 2013);

- as evidentes dificuldades do saber biomédico em lidar com a morte e o morrer, ainda que a possibilidade da morte tenha sido deslocada para o hospital (Aredes e Modesto, 2016; Kovács, 2014; Rodrigues, 2006; Menezes, 2004; Foucault, 2003).

Este médico jovem discutiu as dificuldades experimentadas no cotidiano:

Eu acho que é essa manutenção da vida a todo custo. Hoje eles [a sociedade] pensam que a nossa função é essa. (...) você vê o terceiro andar [unidade de crônicos], você viu e eu tenho certeza que você mudou sua concepção de morte. Se você perguntar a qualquer familiar daqueles pacientes, no dia da cirurgia [de posicionamento da coluna, sem propósito de cura], se você explicasse a eles [na porta de entrada] que isso iria acontecer, eles iam responder: "eu quero que opere, eu quero ele vivo comigo". (...) Então tem muitas coisas em questão, e na hora fica difícil você definir o que fazer (E19, neurocirurgia, M, 32 anos).

O mesmo profissional buscou justificativas compensatórias ao ter de anunciar o óbito:

Eu sempre tento jogar o outro lado: se ele tivesse sobrevivido ele iria sobreviver vegetando (...) à custa de sequelas irreversíveis, e eu vejo os familiares se apegando muito nisso (E19, neurocirurgia, M, 32 anos).

Assim, a medicina moderna 'fabrica' pessoas em estado crônico vegetativo (ECV) ou em estados paucirrelacionais crônicos, que não mostram capacidade de responder a estímulos, de falar, compreender, de se relacionar nem de controlar seus esfíncteres (Aubry, 2008). Ainda que busque manter certo distanciamento físico e mental diante do sujeito limitado (Aredes e Modesto, 2016; Silva e Menezes, 2015), o profissional não consegue demover os familiares da vontade de lutar pela vida de seus entes. Por sua vez, o médico (re)encontra diuturnamente 'condições intransponíveis' que lhe causam compaixão, culpa, desconforto, especialmente em 
relação à perspectiva de lidar com desfechos não desejados do cuidado médico. Tais situações se traduzem em diferentes signos que aparecem em destaque no Quadro 2.

\section{Quadro 2}

\begin{tabular}{|c|c|}
\hline SIGNOS & $\begin{array}{l}\text { SIGNIFICADOS (Condições } \\
\text { Intransponíveis) }\end{array}$ \\
\hline $\begin{array}{l}\text { “Ter um paciente sem prognóstico na sua mão, é difícil de lidar (...) a questão do } \\
\text { vagaroso é mais difícil para mim". (E9, Cirurgia Geral, F, } 38 \text { anos) } \\
\text { "Quando você não consegue ter nenhum contato com o paciente e você vê } \\
\text { que ele está apodrecendo em vida a gente sente muita limitação. É um paciente } \\
\text { difícil, a gente tem desconforto em lidar. Você não pode fazer nada para mudar". } \\
\text { (...) A morte do sofrimento prolongado (...) o caminho para a morte em si é o pior } \\
\text { (...). Essa morte arrastada, cheia de feridas, escaras, dentro de um hospital. Eu } \\
\text { acho terrível". (E32, Clínica Médica, F, } 56 \text { anos) }\end{array}$ & $\begin{array}{l}\text { Pessoa que experimenta a } \\
\text { morte física em potência e } \\
\text { o lento e sofrido processo } \\
\text { de morrer. }\end{array}$ \\
\hline $\begin{array}{l}\text { “Os TRM's (Traumatismo Raquimedular) acabam comigo. Não é um prognóstico } \\
\text { de morte. É um prognóstico de má qualidade de vida (...) Ficar dependente, não } \\
\text { poder trabalhar, não poder estudar, não poder amar, não poder ter filhos ou não } \\
\text { poder cuidar dos filhos, não poder ter uma vida social, eu acho essa morte mais } \\
\text { doída do que a morte mesmo". (E30, Clínica Médica, F, } 44 \text { anos) }\end{array}$ & $\begin{array}{l}\text { Pessoa que vivencia a } \\
\text { perda da funcionalidade } \\
\text { e configura um sujeito } \\
\text { cuja vida será piorada pela } \\
\text { gravidade da sequela e por } \\
\text { sua impotência. }\end{array}$ \\
\hline $\begin{array}{l}\text { "Um hospital superlotado como esse, você precisa pensar que os que estão } \\
\text { chegando precisam de espaço, e o paciente sem prognóstico está ocupando } \\
\text { um espaço". (E21, Clínica Médica, M, } 34 \text { anos) }\end{array}$ & $\begin{array}{l}\text { Retira a chance de alguém } \\
\text { com potencial de cura, pois } \\
\text { encontra-se em um local } \\
\text { indevido para a cronicidade. }\end{array}$ \\
\hline $\begin{array}{l}\text { “Principalmente que esses casos são mal regulamentados no Brasil, a distanásia, } \\
\text { eutanásia; nós não temos respaldo nenhum praticamente. Vejo colegas fazendo } \\
\text { investimento em pacientes em vão, porque eles não vão se recuperar (...) o médico } \\
\text { tem essa postura com receio de processos". (E22, Clínica Médica, M, } 33 \text { anos) } \\
\text { “Na faculdade eles te ensinam tudo o que você precisa fazer para manter o } \\
\text { doente vivo até o dia que o seu doente morre. Aí você tem que lidar com a } \\
\text { primeira frustração da sua vida”. (E11, Cirurgia Geral, M, } 39 \text { anos) } \\
\text { "A morte dos seus pacientes é aquilo que você tem que evitar a todo custo, } \\
\text { afinal nenhum médico quer perder o seu paciente, é um objetivo técnico: } \\
\text { não morrer". (E41, Clínica Médica, M, } 38 \text { anos) }\end{array}$ & $\begin{array}{l}\text { Obstinação terapêutica e } \\
\text { limitações da medicina em } \\
\text { lidar com a morte }\end{array}$ \\
\hline $\begin{array}{l}\text { “Tem coisas que não adianta conversar com a família (...). É muito difícil passar } \\
\text { a gravidade de um quadro para um leigo (...) tem familiares que acham que a } \\
\text { gente está matando o familiar dele. (E22, Clínica Médica, M, } 33 \text { anos) } \\
\text { "Você chama eles aqui e fala que o paciente está de alta. Eles chegam e vê um } \\
\text { sequeladão de todo tamanho. Tem família que foge, isso assusta. A maioria não tem } \\
\text { condições: são pacientes que demandam muito. A assistente social vai até a casa } \\
\text { dessas pessoas e às vezes tem } 6 \text { pessoas dormindo num cômodo só, como eles vão } \\
\text { acolher o sequelado? Isso é terrível é só a gente pensar na gente. Veja-se sequelado: } \\
\text { o peso que você vai ser para sua família!?". (E29, Clínica Médica, M, } 63 \text { anos) }\end{array}$ & $\begin{array}{l}\text { Limitações dos familiares } \\
\text { diante do paciente crônico- } \\
\text { sequelado }\end{array}$ \\
\hline $\begin{array}{l}\text { "No Brasil é muito difícil devido as religiões, de que não se deve morrer, e ao dizer } \\
\text { sobre limitação, as pessoas comentam que para Deus nada é impossível". (E34, } \\
\text { Clínica Médica, F, } 29 \text { anos) } \\
\text { "Os evangélicos ficam um tempo danado ao lado da gente para ver se não vamos } \\
\text { desligar os aparelhos (...). Nós somos quase que um obstáculo para o milagre dos } \\
\text { evangélicos. Os católicos pensam mais que a gente está do lado deles, eles falam } \\
\text { muito de instrumento na mão de Deus". (E36, Pediatria, M, } 46 \text { anos) }\end{array}$ & Apelo a crenças e religiões \\
\hline
\end{tabular}

Fonte: As autoras. 
Em sua práxis, o médico reflete sobre a sua atuação, de modo a reelaborar quais seriam os significados de vida e de morte. Os signos 'sofrimento prolongado', 'apodrecendo em vida', 'morte arrastada' denotam a perspectiva de um lento processo até a consumação da morte biológica (Fontes e Martins, 2015). 'Prognóstico de má qualidade de vida' e 'dependente' dizem respeito à grave limitação funcional que impossibilita o paciente de interagir plenamente com o meio em que vive e desafia o domínio do saber biomédico sobre o corpo e a vida (Classificação Internacional de Funcionalidade, Incapacidade e Saúde, 2004). Quanto ao signo 'Ocupando um espaço', ele alude à carência de leitos e à opção da medicina em privilegiar o cuidado com propósito curativo, embora ela possa resultar na sobrevivência de pessoas gravemente incapacitadas (Aubry, 2008). Segundo Le Breton (2007, p. 76), esse sujeito - socialmente demarcado pela mudança radical em prejuízo da sua funcionalidade -, ao contrariar a hegemonia da norma, adquire um estatuto intermediário/ um meio termo, não estando morto, nem completamente vivo, "nem fora da sociedade, nem dentro dela".

Outras questões disfuncionais da saúde pública, como a insuficiência de leitos de retaguarda e de reabilitação (Conselho Federal de Medicina, 2011), também geram conflitos, dilemas éticos e sofrimentos diretamente relacionados às inconsistências entre os procedimentos biomédicos cabíveis à recuperação da saúde dos pacientes e os gargalos institucionais que bloqueiam sua efetivação (Rosado, Russo e Maia, 2015).

Por sua vez, a dificuldade da sociedade diante da morte e sua cobrança para investir em pacientes muito graves (Silva, Quintana e Nietsche, 2012) leva o profissional a se submeter ("receio de processos; não temos respaldo; objetivo técnico: não morrer"), mesmo que contrariando evidências científicas. O médico pode ser questionado quanto à prática da distanásia (Lôbo Marreiro, 2013), segundo a qual lhe seriam imputados os danos sofridos pelos pacientes, pois a sustentação artificial obstinada das funções vitais - futilidade terapêutica - pode afetar a dignidade humana (Baruzzi e Ikeoka, 2013). No Brasil, contribuem para isso o desconhecimento e a fragilidade das regulamentações existentes sobre cuidados paliativos e a ortotanásia, que desaconselham o uso de métodos desproporcionais de prolongamento da vida, a fim de assegurar uma morte digna ao paciente terminal (Bomtempo, 2011).

Uma atuação médica pautada no domínio do saber biomédico (Camargo, 2013) sobre o corpo dos outros (Foucault, 2003; Le Breton, 2007) passa a admitir a morte e a apresentá-la como plausível tendo em vista a 'opção b': sobreviver com sequelas que limitariam, de modo definitivo, a funcionalidade e a participação social do paciente (Le Breton, 2007).

O profissional compreende essa nova condição como um 'fardo e/ou peso social' (Fontes e Martins, 2015). Quando o paciente encontra-se em condição de alta hospitalar do ponto de vista clínico, ficam evidentes as limitações dos 
familiares no cuidado ao paciente 'crônico-sequelado' (definido pelos signos: 'sequeladão', 'peso'). Falta-lhes a garantia da integralidade do cuidado (Kalichman e Ayres, 2016): o serviço e a rede pública não oferecem condições para reabilitação de maior complexidade nem dispõem de uma política de cuidados prolongados que apoie pacientes e familiares (Romero et al., 2010).

Esta profissional discorreu sobre seus conflitos diante de um paciente sem prognóstico:

Eu tenho muito medo da futilidade terapêutica, de estar fazendo para mim e não para ele. Isso é para que eu não perca o paciente ou porque é bom para ele? Essa é a minha pergunta eterna. Eu tenho um paciente sem prognóstico que eu olho há nove anos, está em estado vegetativo permanente (...). Eu fico pensando: se ele morrer, eu vou sentir como um fracasso pessoal? Ele já teve situações em que quase morreu, mas eu interferi e não deixei. Será que eu estou fazendo isso para ele ou para mim? (E39, pediatria-CTI, F, 58 anos).

Médicos, especialmente de UTI pediátrica, enfrentam conflitos no que se refere à obstinação terapêutica. A inclusão de assuntos relacionados à bioética e à tomada de decisões médicas no ambiente hospitalar contribui para a formação ética e moral dos profissionais (Martinez e Velarde, 2013). Contudo, a expectativa social de que não se deve morrer espelha a negação da morte, sustentada em crenças religiosas:

É muito difícil você cuidar de um paciente sem prognóstico, porque eu preciso lidar com o sofrimento daquela família, eu preciso fazer com que eles entendam que aquele paciente não tem prognóstico, eu gostaria que aquilo fosse mais breve, (...) eu tenho que lidar com o todo da UTI, a técnica de enfermagem que é evangélica e que está esperando o mesmo milagre que a mãe (...) (E36, pediatria-CTI, M, 46 anos).

Na falta de recursos, o 'apelo religioso' também participa da compreensão desse processo. Na cultura local, sob influência cristã, as religiões buscam dar sentido aos acontecimentos da vida, reforçam a imagem social de que 'não se deve morrer' e possibilitam que a pessoa compreenda tais significados como parte de um propósito mais amplo, determinado por uma força superior (Xavier, Miziara e Miziara, 2014). Porém, a forma de lidar com a condição crônica depende da biografia, do modo de vida, da crença de todos os envolvidos pacientes, familiares, médicos -, que é sempre relativa, e pode se modificar ao longo do processo de acompanhamento, adoecimento e morte. Todos podem negar, projetar, desejar, temer, ocultar a mesma verdade: somos todos, médicos e pacientes, seres de sentimentos e histórias, frágeis, finitos, mortais. 
Estes médicos reconheceram que a morte ou a sobrevivência de um paciente sequelado podem gerar sofrimento no profissional:

O médico de pronto socorro coloca um escudo na frente dele: da urgência e da emergência. (...) Para não se expor, não perder tempo, não se desgastar, não sofrer, para deixar as suas questões de morte guardadas (E33, terapia intensiva, F, 34 anos).

O médico tem que ter uma postura fria, porque absorver a dor dos outros é uma coisa complexa. Eu saio da minha casa todos os dias e vou para o epicentro do tumulto, eu vou para onde todo mundo quer fugir (...). Você tem que ter uma certa blindagem, mas isso não significa que você seja frio (E31, clínica médica, M, 58 anos).

Em sua prática profissional, os médicos fazem uso de uma postura resistente para encobrir sua sobrecarga física e mental diante do sofrimento alheio (Aredes e Modesto, 2016), o que não os impede de se afetar. Essa 'blindagem' busca disfarçar suas dificuldades em criar vínculos, inerentes ao tratamento crônico de um paciente grave e definitivamente incapacitado, bem como encobrir certas manifestações sutis de sensibilidade em relação ao outro (Aredes e Modesto, 2016) e proteger a si e aos outros (Nogueira Filho, 2010) das frustrações ante os limites da medicina.

Durante o período de campo, um profissional ressaltou a importância de ações focadas na saúde do médico como trabalhador:

Eu acho que esse preparo psicológico tinha que ser feito. Tem muito médico surtando por aí. Aqui no hospital mesmo, temos vários exemplos de crises de estresse, agressão. Recentemente, uma residente se suicidou, enforcando-se. A garota era linda, com vida social normal, com uma carreira invejada (...). Mas você concorda comigo que algo certamente não estava indo bem com ela, e essa ajuda psicológica talvez seria uma medida preventiva para esses casos, quem sabe se ela tivesse sido acompanhada isso não teria sido evitado? (E11, cirurgia geral, M, 39 anos).

Especialmente no contexto de pronto socorro, o exercício profissional, a carreira médica, o lidar com a morte e com o sofrimento podem ser estressantes a ponto de interferir na própria saúde e na vida do médico (Rosado, Russo e Maia, 2015), com casos de depressão e uso abusivo de álcool (Santos et al., 2017), além da síndrome de burnout. Esta última caracteriza-se por exaustão emocional, despersonalização e baixa realização pessoal - é comum em médicos expostos a um alto nível de estresse no trabalho, com impacto negativo no cuidado ao paciente e na qualidade de vida do profissional (Romani e Ashkar, 2014). O apoio psicológico seria uma das ações essenciais para resguardar a saúde dos profissionais e, como 
consequência, a qualidade da assistência ao usuário (Rosado, Russo e Maia, 2015). Um estudo apontou índices mais elevados de adoecimento em profissionais que atuam em hospitais públicos em comparação com os hospitais privados. Uma das razões apontadas pelos autores seria a existência, no âmbito privado, de recursos mais eficazes para o profissional lidar com as adversidades com as quais ele se depara na prática profissional (Santos et al., 2017). Além disso, o diagnóstico de uma condição incurável ou potencialmente letal provoca reações no indivíduo, em seus próximos e no profissional, em um processo que desloca os que estão em processo de morte para os bastidores da vida social (Elias, 1982).

Perguntada sobre qual seria o pior tipo de morte, esta médica ponderou:

Se eu estivesse na condição de um paciente tetraplégico, (...) me sentiria morta, com o compromisso de estar viva biologicamente. É uma morte em vida que se estende para todo o redor (...). Essa morte social que tem aqui é uma morte mais difícil do que a morte propriamente dita (E30, clínica médica, F, 44 anos).

Transversal a todos os signos que remetem a um paciente 'crônico-sequelado' subjaz o termo êmico 'morte em vida', que traduz uma 'morte social' (Gurgel, 2007) ocorrida antes do óbito e implica importantes perdas de papéis. No pronto atendimento, observa-se a mesma lógica de uma sociedade que produz o trauma e as DCNT e impõe ao sistema de saúde a obrigação de reparar o indivíduo e devolvê-lo em condições de produção (Bauman, 2001). Essa concepção de vida e de morte reflete preceitos capitalistas segundo os quais a sociedade deveria investir somente em pessoas potencialmente produtivas.

A perspectiva ocidental de considerar manter a 'vida a todo custo' como 'sucesso' e a morte como um 'fracasso' prolonga o processo de morrer com sofrimento (Baruzzi e Ikeoka, 2013) e deixa os sobreviventes ainda mais vulneráveis aos agravos em saúde, à exclusão social e à própria violência (Fontes e Martins, 2015). Para Fassin (2010), um corpo portador de um mal passa a ser reconhecido pelo seu sofrimento. Assim, o corpo torna-se o local onde a compaixão pode ser exercida. O referido autor define a compaixão vinculada a sentimentos como empatia, sensibilidade ao mal-estar do outro, bem como uma busca pela proximidade.

Ainda que, em um 'ato de compaixão', o médico transfira para si o infortúnio experienciado pelo paciente (Wenceslau, Portocarrero-Gross e Demarzo, 2016), ancorado em liames que submergem as esferas éticas, profissionais e subjetivas (Aredes e Modesto, 2016), ele erra porque embora o saber biomédico estabeleça os limites da atuação do profissional (exames, procedimentos, meios que confirmam ou não as chances de êxito), ao mesmo tempo o força a continuar intervindo por esses mesmos meios. Ao resistir aos limites de até onde intervir (Kovács, 2014), o profissional acaba por ultrapassá-los, ficando exposto a um conflito ético. 
Assim, paradoxalmente cobrado para e por obedecer ao modelo biomédico (Camargo, 2013), o profissional é apenas mais uma peça na engrenagem complexa de uma sociedade inserida em um mosaico de contextos específicos, moldados por aspectos tão diversos quanto a sensibilidade humana, a violência urbana (Deslandes, 2002; Murray, Cerqueira e Kahn, 2013) e as crenças religiosas (Xavier, Miziara e Miziara, 2014), cujos reflexos a dinâmica de um pronto socorro permite desvelar. Fassin (2010) destaca que os sentimentos morais tornam-se um elemento crucial das políticas contemporâneas, pois permeiam os discursos políticos e legitimam as práticas coletivas de compaixão.

À guisa de uma síntese abrangente, ética e politicamente implicada, na Figura 2 são apresentadas ambivalências no pensar e no agir do profissional médico em face de um paciente 'crônico-sequelado' cuidado no pronto atendimento. O método etnográfico permite revelar situações latentes que se manifestam mediante a conjugação da observação empírica com as entrevistas. Caso nos ativéssemos somente ao relato dos entrevistados, esses novos dados não se revelariam. Talvez a inconsistência existente entre 'o que dizem e o que fazem' espelhe a estrutura institucional biomédica a que pertencem, na qual a luta pela vida e pela cura deve se sobrepor ao longo do cuidado (Aredes e Modesto, 2016).

Figura 1

Ambivalências no pensar e no agir do profissional médico no cuidado ao paciente 'crônico-sequelado'

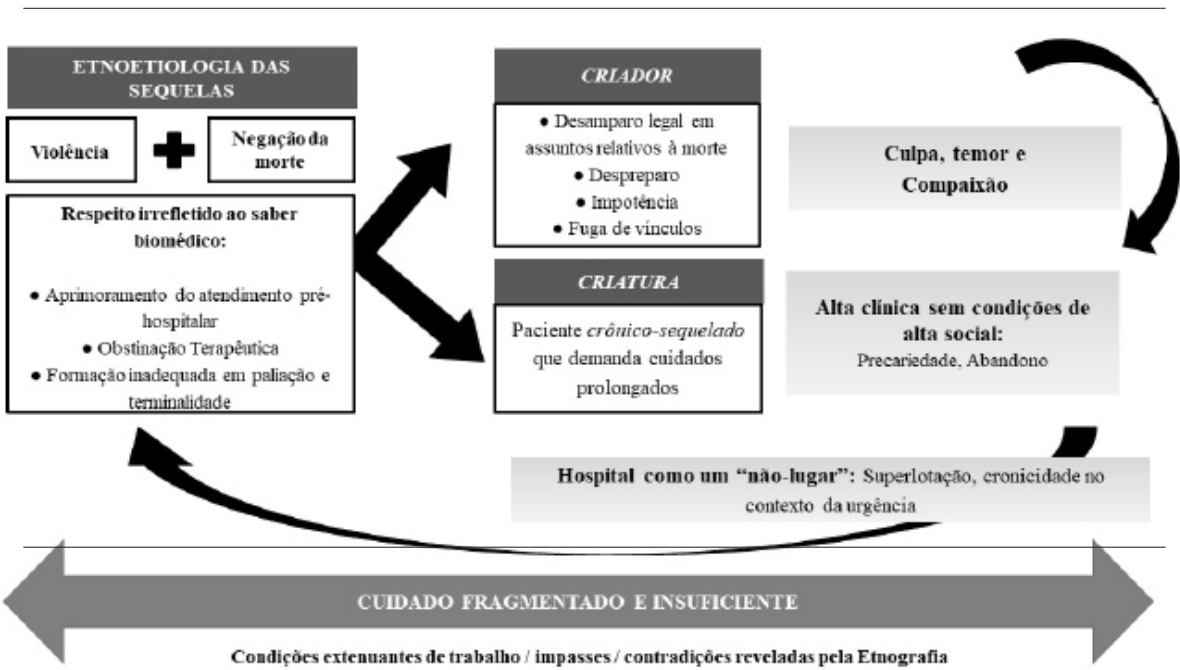

Fonte: As autoras.

Este diagrama (Figura 1) pretende conjugar os vários aspectos envolvidos no esforço que os médicos fazem para cuidar, ainda que de modo fragmentado e insuficiente, em uma instituição de cuidados ágeis e relações voláteis que remetem ao não lugar proposto por Augé (1994). Nesse território de passagem, mediado por relações fugazes e protegidas por 'escudos', a cronicidade (Canesqui, 2013) não encontra uma posição definida. 
A presença de pacientes crônicos em um serviço de urgência repercute na vida institucional, profissional e familiar. Sobram cobranças pelo que o médico fez e pelo que ele não conseguiu fazer, pois o que está em jogo é a manutenção biológica da vida. Ele sofre diante da 'Criatura' que ajudou a criar, pois ela configura a um só tempo a materialização do seu fracasso e/ou da sua obstinação terapêutica, bem como revela o que foi ou não realizado nos diferentes contextos de cuidado, em termos técnicos, humanos e éticos. Essas circunstâncias também afetam a qualidade de vida e de morte dos pacientes (Siqueira, Pessine e Siqueira, 2013). Para Fassin (2010), é necessário pensar de modo concreto como a vida humana é tratada, não apenas restrita a uma questão de discursos e tecnologias, mas sobretudo em nome de quais princípios morais.

Nas sombras de uma etnografia (Mclean e Leibing, 2007), é possível perceber emoções ambivalentes e limites em todos os envolvidos e ampliar a compreensão da etnoetiologia (Calvasina et al., 2007) de pessoas com sequelas graves e definitivas. Uma sociedade violenta somada à atuação de um profissional que exerce o modelo biomédico de maneira irrefletida para atender às expectativas de familiares e pacientes - enquanto se submete a condições extenuantes de trabalho - revela uma verdadeira medicina de guerra. Por sua vez, faltam recursos ao médico (formação, impotência e solidão, ausência de espaço para discussão de casos com a equipe, os pacientes e os familiares), ao serviço (condições de trabalho, insuficiência de reabilitação de maior complexidade e de cuidados prolongados na rede pública), aos familiares, à sociedade, inclusive de sustentação legal para atuação médica e de proteção aos pacientes.

Por não saber como assistir a morte de alguém como 'Criador', o profissional experimenta culpa, medo e compaixão pela 'Criatura' que, ao impedir de morrer, condenou a não viver em uma sociedade que não admite um indivíduo que contrarie a hegemonia da norma (Le Breton, 2007).

\section{Considerações finais}

A etnografia aqui apresentada procurou desvelar uma questão fundamental que perpassa o cuidado e a atuação médica: os conceitos de vida e morte, revistos e atualizados na prática cotidiana em um pronto socorro. Um contexto que expõe as mazelas da sociedade brasileira em todo o seu espectro, sobretudo a violência, a exclusão social, os desafios e os limites da saúde pública.

Em uma unidade de pronto socorro, a sequela adquirida materializa o desfecho de um cuidado médico que contraria as expectativas de todos os envolvidos, pois resulta em uma condição grave e definitivamente incapacitante. Cotidianamente confrontados com seus próprios limites e aqueles do serviço, dos pacientes e familiares, os médicos atribuem a gênese de pacientes 'crônico-sequelados' à atuação da medicina e à violência - a primeira ancorada ao modelo biomédico que atribui o êxito do trabalho médico à manutenção 
irrefletida da vida biológica, enquanto a segunda configura-se como um grave problema de saúde pública no Brasil, uma vez que a cronicidade desses pacientes no serviço de urgência compromete seu cuidado e sua reabilitação.

Nesse contexto, os médicos questionam a finalidade da sua atuação e se reconhecem despreparados para lidar com a inescapável condição humana de fragilidade, imperfeição e finitude. Para amortecer sentimentos e emoções e continuarem atuando como se espera deles, portam escudos que os mantêm à distância e sofrem incompreensões. Além disso, no cuidado a um paciente 'crônico-sequelado' revelam-se os temores do médico: o excesso ou a falta de investimento espelha o seu fracasso como profissional. O saber biomédico e a pressão da sociedade exigem uma atuação obstinada do médico contra a morte, desconhecendo que não se trata de uma escolha binária: investir ou não investir na vida, mas de reconhecer os vários limites do cuidado - os do profissional, os dos pacientes, os das famílias e os do serviço.

Para alterar esse cenário, será necessário investir na formação paliativista para superar a visão pessimista do modelo biomédico sobre as limitações funcionais, bem como promover debates sobre os limites éticos que definem a qualidade de vida e de morte. Cabe ainda reconhecer os esforços dos médicos para superar as próprias angústias e serem compassivos com os pacientes e suas famílias. Porém, isso não fará sentido se não forem implantadas políticas de prevenção e enfrentamento da violência, bem como de oferta de leitos de retaguarda e de cuidados de longa duração para pessoas com deficiências adquiridas que possibilitem um cuidado digno e adequado a cada situação, em todas as fases do curso da vida.

\section{Colaboradores}

Janaína de Souza Aredes trabalhou na concepção e no planejamento do projeto, coleta, análise e interpretação dos dados; contribuiu na elaboração do rascunho e na revisão crítica relevante do conteúdo intelectual; e participou da aprovação da versão final do manuscrito. Karla Cristina Giacomin e Josélia Oliveira Araújo Firmo trabalharam na concepção e no planejamento do projeto, análise e interpretação dos dados; contribuíram na elaboração do rascunho e na revisão crítica relevante do conteúdo intelectual; e participaram da aprovação da versão final do manuscrito. Todas as autoras colaboraram na redação do manuscrito. Declaramos que não há conflitos de interesse. 
Resumen ¿Cuál es la relación entre las urgencias y el cuidado crónico? Esta cuestión, aparentemente paradójica, se abordó en una etnografía realizada en el mayor hospital de urgencias de una metrópolis brasileña, en la cual se investigó el cuidado médico desde la admisión hasta la ratificación de la situación clínico funcional del paciente con graves secuelas. Entre diciembre del 2012 y agosto del 2013 se realizaron observación participante y entrevistas con 43 médicos: 25 hombres y 18 mujeres, con edades entre 28 y 69 años. El análisis, guiado por el modelo de signos, significados y acciones, permitió constatar que el cuidado varía de acuerdo con el contexto: en la 'puerta de ingreso' y en la 'unidad de cuidados intensivos' se lucha intensamente por mantener al paciente con vida; en el sector 'crónicos' se cuida a personas que sobreviven, pero con alto grado de dependencia. Para el médico, 'vida' significa la recuperación de la funcionalidad previa, mientras que sobrevivir con dependencia sería una 'muerte en vida'. El médico elude el hecho de tratar a un ser humano altamente limitado, ya que se siente de alguna manera culpado por el cuadro, a pesar de compadecerse ante un paciente que demanda cuidados crónicos. La insuficiencia de una red de cuidados continuados y la falta de formación del médico en cuidados paliativos generan sufrimientos tanto a quien cuida como a quien es cuidado.

Palabras clave cuidados de la salud; cuadro crónico; discapacidad; urgencia.

\section{Notas}

${ }^{1}$ Fundação Oswaldo Cruz, Instituto René Rachou, Programa de Pós-Graduação em Saúde Coletiva, Belo Horizonte, Minas Gerais, Brasil.

$<$ janainaaredes@gmail.com>

Correspondência: Avenida Augusto de Lima, 1.715, Barro Preto, CEP 30190-002, Belo Horizonte, Minas Gerais, Brasil.

${ }^{2}$ Prefeitura de Belo Horizonte, Secretaria Municipal de Saúde, Belo Horizonte, Minas Gerais, Brasil.

$<$ kcgiacomin@hotmail.com>

${ }^{3}$ Fundação Oswaldo Cruz, Instituto René Rachou, Núcleo de Estudos em Saúde Pública e Envelhecimento, Belo Horizonte, Minas Gerais, Brasil.

$<$ firmoj@cpqrr.fiocruz.br>

${ }^{4}$ Este artigo compõe um dos resultados do projeto de doutorado a ser apresentado ao Programa de Pós-Graduação, financiado pelo Conselho Nacional de Desenvolvimento Científico e Tecnológico (CNPq) - bolsa de produtividade n. 303372/2014-1 - e pela Coordenação de Aperfeiçoamento de Pessoal de Nível Superior (Capes) - bolsa de doutorado. 


\section{Referências}

AREDES, Janaína S. et al. Reflexões sobre um fazer etnográfico no pronto socorro. Cadernos de Saúde Pública, Rio de Janeiro, v. 33, n. 9, 2017.

AREDES, Janaína S; MODESTO, Ana L. 'Entre vidas e mortes, entre máscaras e fugas': um estudo sobre a prática médica hospitalar. Physis: Revista de Saúde Coletiva, Rio de Janeiro, v. 26, n. 2, p. 435-453, 2016.

AUBRY, Régis. L'alimentation artificielle et l'hydratation chez la personne en état végétatif chronique: soin, traitement ou acharnement thérapeutique? Médecine Palliative: soins de support-accompagnement-éthique, v. 7, n. 2, p. 74-85, 2008.

AUGÉ, Marc. Não-lugares: introdução a uma antropologia da supermodernidade. Campinas: Papirus, 1994.

AYRES, José R. Organização das ações de atenção à saúde: modelos e práticas. Saúde e Sociedade, São Paulo, v. 18, supl. 2, p. 11-23, 2009.

BARUZZI, Antônio C.; IKEOKA, Dimas T. Terminalidade e cuidados paliativos em terapia intensiva. Revista da Associação Médica Brasileira, São Paulo, v. 59, n. 6, p. 528-530, 2013.

BAUMAN, Zygmunt. Modernidade líquida. Tradução Plínio Dentzien. Rio de Janeiro: Jorge Zahar, 2001.

BOMTEMPO, Tiago V. A ortotanásia e o direito de morrer com dignidade: uma análise constitucional. Revista Internacional de Direito e Cidadania, n. 9, fev. p. 169-182, 2011.

CALDAS, Celia P. et al. Atendimento de emergência e suas interfaces: o cuidado de curta duração a idosos. Jornal Brasileiro de Economia da Saúde [on-line], São Paulo, v. 7, n. 1, p. 62-69, 2015. Disponível em: <http://files. bvs.br/upload/S/2175-2095/2015/v7nl/a4757. pdf $>$. Acesso em: 25 maio 2017.

CALVASINA, Paola G. et al. 'Fraqueza de nascença': sentidos e significados culturais de impressões maternas na saúde infantil no Nordeste brasileiro. Cadernos de Saúde Pública, Rio de Janeiro, v. 23, n. 2, p. 371-380, 2007.

CAMARGO, Kenneth R. O paradigma clínicoepidemiológico ou biomédico. Revista Brasileira de História da Ciência, Rio de Janeiro, v. 6, n. 2, p. 183-195, 2013.

CANESQUI, Ana M. (org.). Adoecimentos e sofrimentos de longa duração. São Paulo: Hucitec, 2013.

CARRERA, Pricivel M.; OLVER, Ian. The financial hazard of personalized medicine and supportive care. Supportive Care in Cancer, v. 23, n. 12, p. 3.399-3.401, 2015.

CARR, Wilfred. Una teoría para la educación: hacia una investigación educativa crítica. Madrid: Morata, 1996.

CHAZAN, Lilian K. Vestindo o jaleco: reflexões sobre a subjetividade e a posição do etnógrafo em ambiente médico. Cadernos de Campo, São Paulo, v. 13, n. 13, p. 15-32, 2005.

CLASSIFICAÇÃO INTERNACIONAL DE FUNCIONALIDADE, INCAPACIDADE E SAÚDE (CIF). 2004. Disponível em: <http://www. inr.pt/uploads/docs/cif/CIF_port_\%202004. pdf>. Acesso em: 25 maio 2016.

CONSELHO FEDERAL DE MEDICINA (CFM). Falta de leitos e de estrutura de atendimento agravam [sic] crise na rede pública. 2011. Disponível em: < http://portal.cfm.org.br/index. php?option $=$ com_content $\&$ view $=$ article $\&$ id $=223$ 37:falta-de-leitos-e-de-estrutura-de-atendimentoagravam-crise-na-rede-publica \&catid=3:portal $>$. Acesso em: 16 fev. 2016.

CORIN, Ellen; UCHÔA, Elizabeth; BIBEAU, Gilles. Articulation et variations des systèmes de signes, de sens et d'action. Psychopathologie Africaine, v. 24, n. 2, p. 183-204, 1992.

DESLANDES, Suely F. Frágeis deuses: profissionais da emergência entre os danos da 
violência e a recriação da vida. Rio de Janeiro: Editora Fiocruz, 2002.

DINIZ, Eugênio P. H.; PINHEIRO, Letícia C.; PROIETTI, Fernando A. Quando e onde se acidentam e morrem os motociclistas em Belo Horizonte, Minas Gerais, Brasil. Cadernos de Saúde Pública, Rio de Janeiro, v. 31, n. 12, p. 2.621-2.634, 2015.

ELIAS, Norbert. A solidão dos moribundos: seguido de 'Envelhecer e morrer'. 3. ed. Rio de Janeiro: Jorge Zahar, 1982.

FASSIN, Didier. La raison humanitaire: une historie morale du temps présent. Paris: Seuil, Gallimard, 2010.

FONTANELLA, Bruno J. B. et al. Amostragem em pesquisas qualitativas: proposta de procedimentos para constatar saturação teórica. Cadernos de Saúde Pública, Rio de Janeiro, v. 27, n. 2, p. 389-394, 2011.

FONTES, Fernando; MARTINS, Bruno S. Deficiência e inclusão social: os percursos da lesão medular em Portugal. Sociologia, Problemas e Práticas, Lisboa, n. 77, p. 153-172, 2015.

FOUCAULT, Michel. O nascimento da clínica. Rio de Janeiro: Forense Universitária, 2003.

FRANCO, Maria A. S. Práticas pedagógicas de ensinar-aprender: por entre resistências e resignações. Educação e Pesquisa, São Paulo, v. 41, n. 3, p. 601-614, 2015.

FRAZEE, Erin N. et al. Intensive care nurses' knowledge about use of neuromuscular blocking agents in patients with respiratory failure. American Journal of Critical Care, v. 24, n. 5, p. 431-439, 2015.

GEERTZ, Clifford. A interpretação das culturas. Rio de Janeiro: LTC, 1989.

GIACOMIN, Karla C.; FIRMO, Josélia O. A. Old age, disability and care in public health. Ciência \& Saúde Coletiva, Rio de Janeiro, v. 20, n. 12, p. 3.631-3.640, 2015.
GIACOMO, Nelson S. Diretrizes projetuais para unidades de urgência e emergência hospitalares eficientes. 2011. 390f. Tese de Doutorado (Arquitetura e Urbanismo) - Faculdade de Arquitetura e Urbanismo da Universidade de São Paulo, São Paulo, 2011.

GURGEL, Wildoberto B. A morte como questão social. Barbarói, Santa Cruz do Sul, n. 27, p. 60-91, 2007.

KALICHMAN, Artur; AYRES, José Ricardo. Integralidade e tecnologias de atenção à saúde: uma narrativa sobre contribuições conceituais à construção do princípio da integralidade no SUS. Cadernos de Saúde Pública, Rio de Janeiro, v. 32, n. 8, p. e00183415, 2016.

KLEINMAN, Arthur. Patients and healers in the context of cultures. An exploration of borderland between Anthropology and Psychiatry. Berkeley: University of California Press, 1980.

KOVÁCS, Maria J. A caminho da morte com dignidade no século XXI. Revista Bioética, Brasília, v. 22, n. 1, p. 94-104, 2014.

LE BRETON, David. A sociologia do corpo. 2. ed. Tradução de Sônia M. S. Fuhrmann. Petrópolis: Vozes, 2007.

LÔBO MARREIRO, Cecília. Responsabilidade civil do médico na prática da distanásia. Revista Bioética, Brasília, v. 21, n. 2, p. 308-317, 2013.

MARTINEZ, Maria L.; VELARDE, Cristina C. Dilemas bioéticos y sus posibles soluciones em las unidades de terapia intensiva pediátrica del Distrito Federal (México). Acta Bioethica [on-line], Santiago, v. 19, n. 2, p. 275-283, 2013. Disponível em: <https://scielo.conicyt.cl/pdf/abioeth/v19n2/ art12.pdf $>$. Acesso em: 2 jun. 2017.

MAUSS, Marcel. Sociologia e antropologia. São Paulo: Cosac Naify, 2011.

MCLEAN, Athena; LEIBING, Annette (eds.). The shadow side of field work: exploring the blurred borders between ethnography and 
life. 1. ed. Boston: Blackwell/Wileys, 2007. v. 1. 250p.

MENEZES, Rachel A. Em busca da boa morte: antropologia dos cuidados paliativos. Rio de Janeiro: Editora Fiocruz, 2004.

MURRAY, Joseph; CERQUEIRA, Daniel R. C.; KAHN, Tulio. Crime and violence in Brazil: systematic review of time trends, prevalence rates and risk factors. Aggression and Violent Behavior, v. 18, n. 5, p. 471-483, 2013.

NASCIMENTO, Eliane R. P. et al. Ambiência de uma emergência hospitalar para o cuidado ao idoso: percepção dos profissionais de enfermagem. Escola Anna Nery Revista de Enfermagem, Rio de Janeiro, v. 19, n. 2, p. 338-342, 2015.

NEVILLE, Thanh H. et al. Concordance of nurses and physicians on whether critical care patients are receiving futile treatment. American Journal of Critical Care, Los Angeles, v. 24, n. 5, p. 403-410, 2015.

NOGUEIRA FILHO, Luiz N. Desafios do médico na manutenção da esperança dos pacientes gravemente enfermos. Revista Brasileira de Saúde Materno Infantil, Recife, v. 10, supl. 2, p. s279-s287, 2010.

PATTON, Michael Q. Qualitative research and evaluation methods. Londres: Sage Publications, 2002.

ROMANI, Maya; ASHKAR, Khalil. Burnout among physicians. The Libyan Journal of Medicine, v. 9, 2014.

RODRIGUES, José C. Tabu da morte. 2. ed. Rio de Janeiro: Editora Fiocruz, 2006.

ROMERO, Dalia E. et al. Internações de idosos por cuidados prolongados em hospitais do SUS no Rio de Janeiro: uma análise de suas características e da fragilidade das redes sociais de cuidado. In: CAMA-
RANO, Ana A. (org.). Cuidados de longa duração para população idosa: um novo risco social a ser assumido. Rio de Janeiro: Ipea, 2010. p. 249-278.

ROSADO, Iana V. M.; RUSSO, Gláucia H. A.; MAIA, Eulália M. C. Produzir saúde suscita adoecimento? As contradições do trabalho em hospitais públicos de urgência e emergência. Ciência \& Saúde Coletiva, Rio de Janeiro, v. 20, n. 10, p. 3.021-3.032, 2015.

SANTOS, Anelise S. et al. Contexto hospitalar público e privado: impacto no adoecimento mental de trabalhadores da saúde. Trabalho, Educação e Saúde, Rio de Janeiro, v. 15, n. 2, p. 421-438, 2017.

SEMINOTTI, Elisa P.; NEVES, Ednalva M. Dos dramas de Narciso: reflexões antropológicas a partir de uma etnografia de um Serviço de Atendimento Móvel de Urgência (Samu) de João Pessoa-PB. Ilha Revista de Antropologia, Florianópolis, v. 16, n. 1, p. 175-202, 2014.

SILVA, Karla C. O.; QUINTANA, Alberto M.; NIETSCHE, Elisabeta A. Obstinação terapêutica em unidade de terapia intensiva: perspectiva de médicos e enfermeiros. Escola Anna Nery Revista de Enfermagem, Rio de Janeiro, v. 16, n. 4, p. 697-703, 2012.

SILVA, Nathalia R.; MENEZES, Rachel A. 'Se parar, parou': categorização do morrer em uma unidade de terapia intensiva da cidade do Rio de Janeiro. Physis: Revista de Saúde Coletiva, Rio de Janeiro, v. 25, n. 1, p. 265-285, 2015.

SILVA, Sander M.; RAMOS, Márcia Z. Profissionais de saúde de um serviço de emergência hospitalar: discursividades em torno do cuidado. Physis: Revista de Saúde Coletiva, Rio de Janeiro, v. 24, n. 3, p. 693-714, 2014.

SIQUEIRA, José E.; PESSINI, Leo; SIQUEIRA, Carlos E. M. Conflitos morais sobre a termina- 
lidade da vida: aspectos médicos, filosóficos e jurídicos. Revista Colombiana de Bioética, Bogotá, v. 8, n. 2, p. 104-115, 2013.

XAVIER, Marcelo S.; MIZIARA, Carmen S. M G.; MIZIARA, Ivan D. Terminalidade da vida: questões éticas e religiosas sobre a ortotanásia. Saúde, Ética \& Justiça, São Paulo, v. 19, n. 1, p. 26-34, 2014.
WENCESLAU, Leandro D.; PORTOCARREROGROSS, Eberhart; DEMARZO, Marcelo P. Compaixão e medicina centrada na pessoa: convergências entre o Dalai Lama Tenzin Gyatso e Ian McWhinney. Revista Brasileira de Medicina de Família e Comunidade, Rio de Janeiro, v. 11, n. 38, p. 1-10, 2016.

Recebido em 05/09/2017.

Aprovado em 23/01/2018. 